\title{
Statistik demografi Dolichotetranychus floridanus Banks pada dua kultivar nanas (Ananas comosus (L.) Merr.)
}

\section{Demographic statistics of Dolichotetranychus floridanus Banks on two cultivars of pineapple (Ananas comosus (L.) Merr.)}

\author{
Ariffatchur Fauzia ${ }^{\mathrm{a}}$, Sugeng Santoso ${ }^{\mathrm{b}}$, Ali Nurmansyah ${ }^{\mathrm{b}}$ \\ ${ }^{a}$ Mahasiswa Pascasarjana Program Studi Entomologi, IPB University, Kampus IPB Dramaga Bogor, 16680, Indonesia \\ ${ }^{\mathrm{b}}$ Departemen Proteksi Tanaman, Fakultas Pertanian, IPB University, Kampus IPB Dramaga Bogor, 16680, Indonesia \\ [+62 251-8629364]
}

\section{Article Info:}

Received: 17 - 12 - 2020

Accepted: 31 - 12 - 2020

Keywords:

False spider mite, pineapple, statistics demography

Corresponding Author: Sugeng Santoso Departemen Proteksi Tanaman,

Fakultas Pertanian, IPB

University;

Tel. +62-251-8629364

Email:

ssantoso@apps.ipb.ac.id

\begin{abstract}
Pineapple is one of important fruit crops in Indonesia. One of important problems in pineapple production is pest infestation. This study aimed to investigate the biology, demography, and life cycle of Dolichotetranychus floridanus Banks on two pineapple cultivars (Queen and Cayenne). Observation of mite development (eggs-adults) were conducted every 6 hours. Adults were observed every day to record the fecundity. The life table was constructed from the survivor and fecundity of $\mathrm{D}$. floridanus. Based on this table, the variables of population growth, including gross reproduction rate $(G R R)$, net reproductive rate $\left(R_{0}\right)$, mean generation time $(T)$ and increase intrinsic rate $(r)$ were determined. The results showed that the development time of larvae and protonymph on Queen cultivar (2.30 and 2.09 days) was shorter than on Cayenne cultivar (2.91 and 3.34 days). On the Queen cultivar, the value of GRR (34.92), $R_{0}$ (18.66), and $r(0.18)$ of D. floridanus were higher than Cayenne cultivar $(31.38,16.43,0.14)$, respectively. The generation time $(T)$ value of this mite on the Queen cultivar (16.64) was shorter than on Cayenne cultivar (20.16). The results showed that Queen is more suitable for D. floridanus than Cayenne cultivar.
\end{abstract}

How to cite (CSE Style $8^{\text {th }}$ Edition):

Fauzi A, Santoso S, Nurmansyah A. 2020. Statistik demografi Dolichotetranychus floridanus Banks pada dua kultivar nanas (Ananas comosus (L.) Merr.). JPSL 10(4): 660-667. http://dx.doi.org/10.29244/jps1.10.4.660-667.

\section{PENDAHULUAN}

Nanas (Ananas comosus) merupakan salah satu tanaman buah penting di Indonesia. Produksi nanas di Indonesia pada tahun 2016 mencapai 1396153 ton, pada tahun 2017 mencapai 1795986 ton, dan pada tahun 2018 sebesar 1805506 ton (BPS, 2018). Tahun 2018, provinsi Lampung, Jawa Tengah, dan Jawa Barat menjadi tiga provinsi terbesar dalam produksi nanas dengan produksi berturut-turut sebesar 622881 ton, 202 823 ton, dan 180802 ton (BPS, 2018). Nanas memberikan devisa negara melalui ekspor, baik berupa ekspor nanas segar maupun nanas yang sudah diolah menjadi produk lain sebesar 8277104 USD (BPS, 2018).

Tahun 2018, tungau Dolichotetranychus floridanus Banks dilaporkan menjadi masalah pada budidaya nanas di PT GGF (Great Giant Food), Lampung. Tungau D. floridanus adalah hama pada nanas yang tersebar di Filipina, Amerika Utara, Jawa (Indonesia), Hawai, dan Jepang (Ehara, 1966). Kerusakan akibat serangan 
tungau $D$. floridanus dapat terjadi pada semua fase pertumbuhan tanaman nanas. Kerusakan jaringan tumbuhan terdapat pada daun, mahkota buah dan bagian buah. Kerugian yang ditimbulkan oleh $D$. floridanus bukan hanya kerusakan langsung akibat aktivitas makan dari tungau tersebut, tetapi juga kerusakan tidak langsung berupa pembusukan jaringan tanaman akibat bakteri. Evans et al. (1993) mengemukakan bahwa bakteri Erwinia chrysanthemi dapat menyebabkan pembusukan daun dengan cara masuk ke jaringan tanaman melalui lesio (luka) pada daun nanas yang ditimbulkan aktivitas makan $D$. floridanus. Pada serangan berat, tungau ini dapat menyebabkan tanaman nanas mati sebelum berbuah.

D. floridanus termasuk dalam Famili Tenuipalpidae. Tungau ini berwarna oranye atau merah, hidup pada bagian basal mahkota buah maupun daun nanas. Tungau ini dilaporkan mulai menginfestasi tanaman dan buah nanas yang disimpan sejak pertanaman monokultur dikembangkan (Poli, 1991). Menurut Baker dan Pritchard (1956), D. floridanus dianggap sebagai hama penting tanaman nanas terutama di Australia. Tungau ini menimbulkan kerusakan yang mengakibatkan kehilangan produksi nanas pada wilayah Queensland, Australia (Poli, 1991). Kerugian yang ditimbulkan D. floridanus pada nanas di wilayah Queensland, Australia mencapai 1 miliar dollar Australia pada periode 1988-1989 (Poli, 1991). D. floridanus banyak menginfestasi rumputrumputan, terutama pada Cynodon dactylon (El-Bishlawy, 1978 dalam Mohammed et al., 1982). Prabheena dan Ramani (2015) melaporkan kehadiran tungau D. floridanus pada tanaman pinang di wilayah Kerala, India.

Penelitian ini menggunakan dua kultivar nanas yang paling banyak dibudidayakan di Indonesia, yaitu kultivar Queen dan Cayenne. Penyusunan strategi pengendalian tungau yang efektif dan efisien memerlukan informasi mengenai biologi dan ekologi. Dua kultivar yang digunakan dalam penelitian ini adalah kultivar yang paling banyak dibudidayakan sehingga hasil penelitian ini dapat dimanfaatkan untuk penyusunan strategi pengendalian $D$. floridanus pada pertanaman nanas di Indonesia. Penelitian ini bertujuan untuk mendapatkan informasi tentang biologi, demografi dan perkembangan D. floridanus pada dua kultivar nanas (Queen dan Cayenne).

\section{METODE}

\section{Lokasi dan Waktu Penelitian}

Penelitian dilaksanakan pada bulan Juli 2018 sampai Maret 2019 di Laboratorium Ekologi Serangga, Departemen Proteksi Tanaman, Fakultas Pertanian, Institut Pertanian Bogor.

\section{Perbanyakan D. floridanus}

Imago D. floridanus diperoleh dari pertanaman nanas PT GGF. Imago dikumpulkan dan ditempatkan pada tanaman nanas hidup agar dapat bertahan hidup selama pengiriman sampel. Perbanyakan tungau dilakukan dalam cawan petri bagian basal daun nanas yang diletakkan pada kapas dan busa plastik. Kapas dan busa dijenuhi dengan air untuk menjaga kesegaran daun nanas, dan untuk mencegah tungau keluar dari cawan petri. Imago dipelihara agar berkembangbiak dan dapat digunakan untuk penelitian selanjutnya.
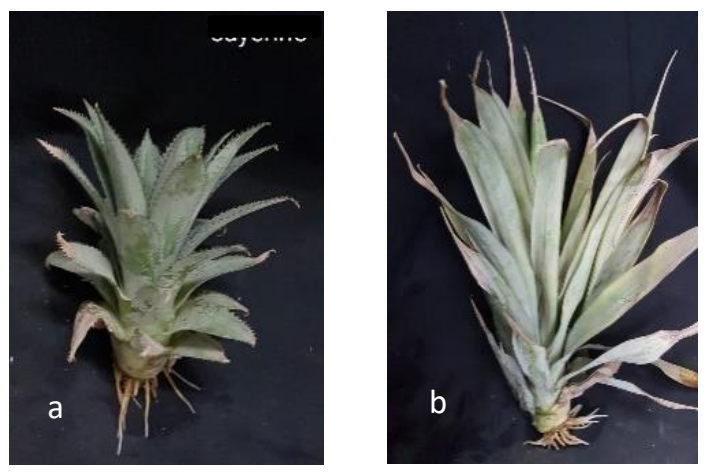

Gambar 1 Kultivar nanas: Cayenne (a) dan Queen (b) 


\section{Pengamatan Perkembangan D. floridanus}

Arena percobaan berupa cawan petri yang berisi bagian basal daun nanas yang diletakkan di atas kapas dan busa plastik yang dijenuhi dengan air. Pada percobaan ini digunakan dua kultivar nanas, yaitu Queen dan Cayenne (Gambar 1). Pada setiap arena percobaan dimasukkan satu butir telur D. floridanus, diletakkan pada permukaan daun nanas. Peletakan telur dilakukan dengan sangat hati-hati dengan kuas sangat halus untuk mencegah terjadinya kerusakan pada telur karena ukuran telur yang sangat kecil. Daun nanas sebagai media hidup dan pakan $D$. floridanus diganti setiap 3 hari agar tungau tetap mendapatkan pakan yang segar dan berkualitas. Pengamatan dilakukan terhadap 75 telur untuk setiap kultivar. Pengamatan dilakukan setiap 6 jam sekali sampai tungau menjadi imago untuk mengetahui perubahan morfologi, lama setiap stadia dan pergantian kulit. Setelah menjadi imago, tungau jantan dan betina dipasang-pasangkan dan diletakkan dalam arena percobaan secara berpasangan. Pengamatan kemudian dilakukan setiap hari (24 jam) sampai imago mati untuk mengetahui keperidian dan lama hidup imago. Suhu dan kelembapan diukur dengan menggunakan termohigrometer.

\section{Penentuan Statistik Demografi dan Kurva Kesintasan Hidup}

Neraca kehidupan (life table) disusun berdasarkan jumlah individu yang hidup pada setiap umur pengamatan $\left(\mathrm{a}_{\mathrm{x}}\right)$, jumlah individu awal $\left(\mathrm{a}_{\mathrm{o}}\right)$, jumlah individu yang mati $\left(\mathrm{d}_{\mathrm{x}}\right)$, proporsi individu yang hidup $\left(\mathrm{l}_{\mathrm{x}}\right)$, dan jumlah telur yang dihasilkan per satuan waktu $(\mathrm{mx})$. Berdasarkan tabel neraca kehidupan ini, 4 statistik demografi utama, yaitu laju reproduksi kotor (GRR), laju reproduksi bersih $\left(\mathrm{R}_{0}\right)$, waktu generasi $(\mathrm{T})$, dan laju pertumbuhan intrinsik (r) ditentukan. Jumlah individu awal (jumlah telur awal) yang digunakan dalam penelitian ini adalah 76 butir untuk kultivar Queen dan 75 butir untuk kultivar Cayenne.

GRR adalah jumlah keturunan betina dari 1 individu betina selama hidupnya yang mencapai umur maksimal (Price, 1997) yang dihitung berdasarkan rumus:

$$
\mathrm{GRR}=\sum \mathrm{m}_{\mathrm{x}}
$$

$\mathrm{R}_{0}$ merupakan jumlah keturunan betina per induk per umur tertentu (x) dalam satu generasi (Southwood dan Henderson, 2000) yang dihitung dengan rumus:

$$
\mathrm{R}_{0}=\sum \mathrm{l}_{\mathrm{x}} \mathrm{m}_{\mathrm{x}}
$$

T adalah waktu yang dibutuhkan oleh suatu organisme untuk berkembang mulai dari telur sampai dengan terbentuk kembali keturunan (Young, 1982). Nilai T dihitung dengan rumus:

$$
\mathrm{T}=\Sigma \mathrm{xl}_{\mathrm{x}} \mathrm{m}_{\mathrm{x}} / \Sigma \mathrm{l}_{\mathrm{x}} \mathrm{m}_{\mathrm{x}}
$$

Laju pertumbuhan intrinsik (r) menggambarkan tingkat kenaikan pertumbuhan populasi dalam keadaan konstan. Nilai $r$ ini dihitung dengan persamaan lotka euler:

$$
\sum_{x=1}^{k+1} e^{-r x} l x m x=1
$$

Dengan $\mathrm{k}$ adalah umur maksimum reproduksi yang ada dalam data kohort. Berdasarkan persamaan tersebut, nilai $r$ diperoleh dari proses iterasi. Nilai yang mungkin dari r, disubtitusikan ke sisi kiri persamaan di atas dengan dugaan awal $r$ dihitung dengan persamaan:

$$
\mathrm{r}=\ln \mathrm{R}_{0} / \mathrm{T}
$$


Iterasi dilakukan sampai dengan nilai pada sisi kiri persamaan lotka euler di atas sama dengan 1. Kurva kesintasan hidup yang menggambarkan pola bertahan hidup dari $D$. floridanus memerlukan komponen nilai proporsi hidup $\left(l_{\mathrm{x}}\right)$ dari fase telur hingga imago. Pada kurva kesintasan, nilai $\mathrm{l}_{\mathrm{x}}$ digunakan sebagai sumbu y dan waktu pengamatan digunakan sebagai sumbu $\mathrm{x}$, sedangkan pada kurva keperidian nilai $\mathrm{m}_{\mathrm{x}}$ digunakan sebagai sumbu y dan waktu pengamatan digunakan sebagai sumbu $\mathrm{x}$.

\section{Analisis Data}

Pemeriksaan perbedaan karakteristik biologi dan statistik demografi $D$. floridanus diuji dengan uji t atau uji z menggunakan piranti lunak Rstudio. Nilai ragam dari keempat statistik demografi (GRR, $R_{0}$, $T$, dan $r$ ) yang diperlukan dalam uji t diduga menggunakan Metode Jackknife.

\section{HASIL DAN PEMBAHASAN}

\section{Morfologi Dolichotetranychus floridanus}

Perkembangan tungau $D$. floridanus dimulai dari telur, larva, protonimfa, deutonimfa dan berakhir pada fase imago (Gambar 2). Telur berwarna merah oranye dan transparan serta memiliki panjang $\pm 0.126 \mathrm{~mm}$. Larva berwarna merah-oranye, memiliki panjang tubuh $\pm 0.129 \mathrm{~mm}$, dan memiliki 3 pasang tungkai. Saat memasuki fase protonimfa, tungkai tungau tersebut berjumlah 4 pasang, tungkai paling depan transparan (tidak berwarna), tubuh berwarna merah oranye dan panjangnya 0.196 hingga $0.200 \mathrm{~mm}$. Tubuh tungau saat memasuki fase deutonimfa berwarna merah, lebih gelap dibandingkan saat protonimfa dan memiliki panjang $\pm 0.252 \mathrm{~mm}$. Ketika menjadi imago, tungau tersebut berwarna merah tua pekat pada tubuh dan tungkainya. Sebagian besar larva acarina memiliki 3 pasang tungkai dan pada fase berikutnya memiliki 4 pasang tungkai (Helle dan Pijnaker, 1985). Imago memiliki tubuh berbentuk pipih, cenderung cekung pada bagian dorsal, panjang tubuh $235 \mu \mathrm{m}$ tanpa rostrum. Apabila dengan rostrum, panjangnya $300 \mu \mathrm{m}$ dengan lebar badan paling besar $120 \mu \mathrm{m}$.
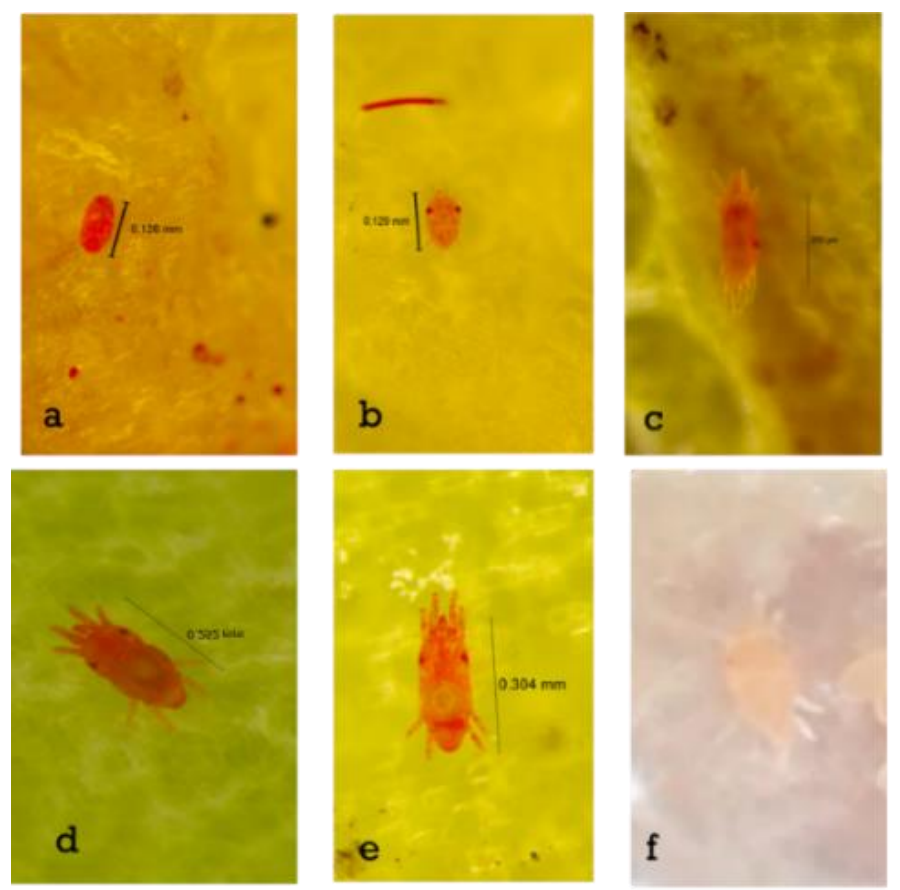

Gambar 2 Fase perkembangan D. floridanus: telur (a), larva (b), protonimfa (c), deutonimfa (d), dan imago betina (e) serta jantan (f) 


\section{Masa Perkembangan D. floridanus pada Dua Kultivar}

Pada kondisi suhu ruang ( 25.5 sampai dengan $27.5^{\circ} \mathrm{C}$ ) dan kelembapan 63 hingga $81 \%$, secara umum, masa pradewasa $D$. floridanus pada kultivar Queen lebih singkat daripada kultivar Cayenne, kecuali untuk fase telur deutonimfa (Tabel 1). Masa perkembangan D. floridanus yang lebih cepat pada kultivar Queen, mengakibatkan imago muncul lebih awal. Waktu kemunculan imago merupakan salah satu faktor penting dalam menekan keberhasilan suatu spesies. Ketersediaan pasangan, kemampuan untuk bertahan pada kondisi cuaca ekstrem, akses terhadap sumber daya dan keberhasilan hidup generasi berikutnya semuanya tergantung pada hubungan yang sinkron antara kemunculan imago dengan ketersediaan sumber daya (Mawan, 2013). Pada penelitian ini, D. floridanus dengan pakan kultivar Queen memiliki kesempatan lebih baik dalam keberhasilan hidup generasi selanjutnya dibandingkan dengan kultivar Cayenne.

Lama hidup imago jantan D. floridanus tidak menunjukkan perbedaan diantara dua kultivar, sedangkan pada masa hidup imago betina menunjukkan imago betina pada kultivar Cayenne (7.37 \pm 0.47$)$ lebih lama dibandingkan dengan imago betina pada kultivar Queen (8.64 \pm 0.35$)$ (Tabel 1). Masa pra oviposisi $D$. floridanus pada kultivar Queen relatif lebih singkat dibandingkan kultivar Cayenne. Masa oviposisi $D$. floridanus pada kultivar Queen lebih lama dibandingkan dengan masa oviposisi pada kultivar Cayenne. Proporsi hidup telur D. floridanus yang dapat mencapai imago pada kultivar Cayenne sebesar $68 \%$, sedangkan pada kultivar Queen mencapai 71\%. Nisbah kelamin imago (betina : jantan) pada kultivar Cayenne adalah $0.86: 0.14$, sedangkan pada kultivar Queen adalah $0.79: 0.21$ (Tabel 1).

Tabel 1 Parameter biologi D. floridanus pada dua kultivar nanas

\begin{tabular}{lccccc}
\hline \multirow{2}{*}{ Parameter biologi } & \multirow{2}{*}{ Satuan } & \multicolumn{4}{c}{ Rata-rata lama stadia pada kultivar- ${ }^{* *}$} \\
\cline { 3 - 6 } & & $\mathrm{n}^{* *}$ & Queen & $\mathrm{n}^{* *}$ & Cayenne \\
\hline Lama stadia & hari & 76 & $3.43 \pm 0.07 \mathrm{a}$ & 75 & $3.31 \pm 0.06 \mathrm{a}$ \\
Telur* & hari & 76 & $2.30 \pm 0.06 \mathrm{~b}$ & 75 & $2.91 \pm 0.09 \mathrm{a}$ \\
Larva* & hari & 55 & $2.09 \pm 0.04 \mathrm{~b}$ & 53 & $3.34 \pm 0.06 \mathrm{a}$ \\
Protonimfa* & hari & 54 & $4.15 \pm 0.06 \mathrm{a}$ & 53 & $4.23 \pm 0.07 \mathrm{a}$ \\
Deutonimfa* & hari & & & & \\
Lama hidup imago & hari & 11 & $6.10 \pm 0.59 \mathrm{a}$ & 7 & $6.29 \pm 0.60 \mathrm{a}$ \\
$\quad$ Jantan* & hari & 43 & $7.37 \pm 0.47 \mathrm{~b}$ & 44 & $8.64 \pm 0.35 \mathrm{a}$ \\
$\quad$ Betina* & hari & 43 & $1.70 \pm 0.25 \mathrm{~b}$ & 44 & $3.41 \pm 0.24 \mathrm{a}$ \\
Masa praoviposisi* & hari & 43 & $6.06 \pm 0.22 \mathrm{a}$ & 44 & $5.36 \pm 0.21 \mathrm{~b}$ \\
Masa oviposisi* & & & & & \\
& butir & 43 & $34.09 \pm 1.75 \mathrm{a}$ & 44 & $31.22 \pm 1.30 \mathrm{a}$ \\
Keperidian* & $\%$ & 54 & 0.79 & 51 & 0.84 \\
Proporsi betina & & &
\end{tabular}

"Nilai pada baris yang sama dan diikuti oleh huruf yang sama tidak menunjukkan beda nyata (uji t atau uji z, $\alpha=5 \%) ;{ }^{* *}$ n: jumlah individu; ${ }^{* * *}$ Angka yang mengikuti tanda $( \pm)$ menunjukkan galat baku.

Kurva kesintasan D. floridanus menggambarkan bahwa peluang hidup mulai menurun sejak individu umur 6 hari (Gambar 3). Setelah terjadi kematian yang tinggi pada awal kehidupan, kematian relatif rendah dialami oleh $D$. floridanus pada dua jenis kultivar. Pada hari ke 15 dan selanjutnya, proporsi hidup $D$. floridanus pada kultivar Queen lebih rendah dibandingkan dengan tungau pada kultivar Cayenne. Kematian tungau pada kultivar Queen hari ke 15 dan selanjutnya terjadi pada fase imago. Masa perkembangan pradewasa D. floridanus pada kultivar Queen lebih singkat dibandingkan dengan Cayenne, sehingga imago muncul lebih awal, menghasilkan keturunan lebih awal (Gambar 3) sehingga mengalami mortalitas setelah proses peletakan telur lebih awal. 
Keperidian harian dituangkan di dalam grafik $\mathrm{m}_{\mathrm{x}}$ (Gambar 4). Pada kultivar Queen, puncak peneluran terjadi pada hari ke-17 (6.49 butir), sedangkan pada Cayenne, puncak peneluran terjadi pada hari ke-21 (5.76 butir). Dengan peneluran $D$. floridanus yang terjadi lebih awal pada kultivar Queen, menyebabkan individu baru lebih cepat muncul dan menimbulkan kerusakan lebih cepat. Kemunculan imago lebih awal diduga berkorelasi dengan jumlah keturunan yang dihasilkan, imago lebih awal muncul akan segera menghasilkan keturunan sehingga jumlah keturunan yang dihasilkan lebih banyak.

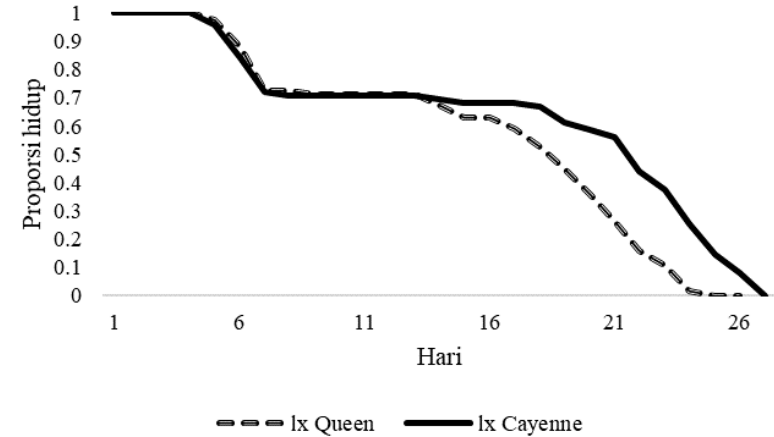

Gambar 3 Kurva kesintasan D. floridanus

-m- Kultivar Queen, -•- Kultivar Cayenne

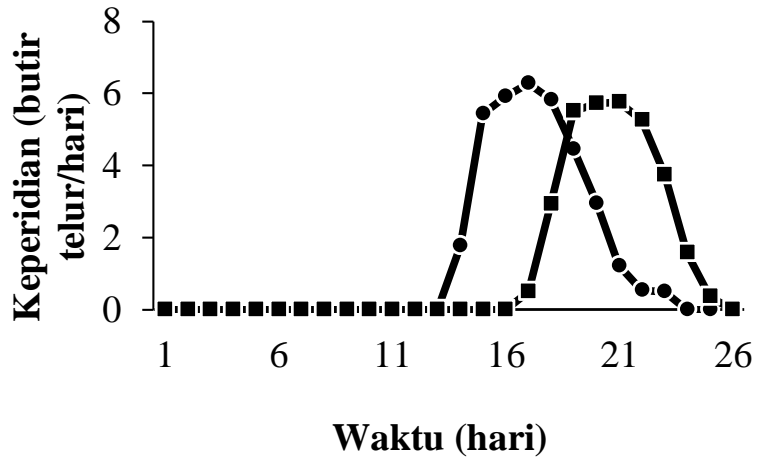

Gambar 4 Kurva keperidian harian D. floridanus pada dua kultivar nanas

- Kultivar Cayenne, -•- Kultivar Queen.

Variasi nilai $1_{\mathrm{x}}$ dan $\mathrm{m}_{\mathrm{x}}$ dapat disebabkan oleh perbedaan kandungan gizi dan kualitas gizi terutama kadar pati dan lemak diantara inang (Laba, 2006). Variasi nilai $1_{x}$ dan $m_{x}$ dapat juga disebabkan oleh antibiosis, yakni senyawa yang bersifat toksik terhadap serangga (Amjad dan Peters, 1992). Kurva kesintasan pada kedua kultivar menunjukkan pola yang sama yaitu kematian pada fase awal tinggi. Menurut Price (1997), terdapat tiga tipe kurva kehidupan: yakni tipe I, II dan III. Hasil penelitian menunjukkan bahwa D. floridanus masuk pada kurva kehidupan tipe III, yaitu menunjukkan kematian tinggi pada populasi umur muda atau masih dalam fase kehidupan awal. Pola ketahanan hidup tipe III ini sangat umum ditemui pada spesies-spesies berukuran tubuh kecil, contohnya serangga (Begon dan Mortimer, 1981).

\section{Statistik Demografi $D$. floridanus pada Dua Kultivar}

Nilai parameter demografi D. floridanus yang meliputi laju reproduksi kotor (GRR), laju reproduksi bersih $\left(\mathrm{R}_{0}\right)$, laju pertambahan intrinsik (r), dan rataan lama generasi $(\mathrm{T})$ dapat dilihat pada Tabel 2. Semua nilai statistik demografi $D$. floridanus berbeda pada dua kultivar nanas yang diujikan. Nilai GRR, $\mathrm{R}_{0}$, dan $\mathrm{r}$ tungau ini pada kultivar Queen lebih tinggi dibandingkan dengan kultivar Cayenne. Masa generasi (T) D. floridanus pada kultivar Queen lebih rendah dibandingkan kultivar Cayenne.

Nilai GRR pada kultivar Queen lebih tinggi dibandingkan Cayenne. Nilai GRR menggambarkan jumlah keturunan betina per induk yang dihasilkan $D$. floridanus yang hidupnya mencapai umur maksimal. Nilai GRR D. floridanus yang hidupnya mencapai 25 hari pada kultivar Queen mampu menghasilkan 34.92 individu per generasinya dan pada Cayenne mampu menghasilkan 31.38 individu per generasi pada tungau yang hidup mencapai 27 hari. Nilai $\mathrm{R}_{0}$ pada kultivar Queen lebih tinggi dibandingkan dengan kultivar Cayenne. Laju reproduksi bersih $\left(\mathrm{R}_{0}\right)$ adalah rataan banyaknya keturunan betina yang dihasilkan oleh satu induk $D$. floridanus. Berdasarkan nilai analisis data, D. floridanus pada kultivar Queen adalah 18.66 dan pada Cayenne adalah 16.43 , artinya populasi $D$. floridanus dapat meningkat 18 kali dari populasi generasi sebelumnya pada kultivar Queen dan meningkat 16 kali. 
Nilai laju intrinsik dapat dijadikan kriteria untuk menilai kesesuaian inang sebuah organisme karena telah memperhitungkan masa perkembangan pradewasa, masa hidup imago, dan sintasan (Price, 1997). Laju pertumbuhan intrinsik (r) pada kultivar Queen lebih tinggi dibandingkan dengan kultivar Cayenne. Nilai r pada kultivar Queen adalah 0.18 dan 0.14 , artinya D. floridanus menghasilkan 0.18 individu/hari pada kultivar Queen dan 0.14 individu/hari pada Cayenne. Nilai r pada penelitian ini menunjukkan bahwa populasi $D$. floridanus lebih cepat bertambah pada kultivar Queen dibandingkan Cayenne karena jumlah individu yang lebih besar dihasilkan setiap harinya. Populasi yang lebih besar membuat kerusakan yang ditimbulkan tungau ini pada tanaman nanas semakin besar. Masa generasi (T) merupakan rata-rata waktu yang diperlukan sejak telur sampai menjadi imago dan meletakkan telur pertama kali. Masa generasi tungau pada kultivar Queen adalah 16.64 dan kultivar Cayenne adalah 20.16. Hal tersebut menunjukkan tungau yang hidup pada daun nanas kultivar Queen dapat mencapai generasi berikutnya dalam waktu 16.64 hari dan 20.16 hari pada kultivar Cayenne.

Tabel 2 Statistik demografi $D$. floridanus pada dua kultivar

\begin{tabular}{ccc}
\hline Parameter & Queen & Cayenne \\
\hline GRR & $34.92 \pm 0.03 \mathrm{a}$ & $31.38 \pm 0.02 \mathrm{~b}$ \\
$\mathrm{R}_{0}$ & $18.66 \pm 0.02 \mathrm{a}$ & $16.43 \pm 0.02 \mathrm{~b}$ \\
$\mathrm{~T}$ & $16.64 \pm 1.5 \times 10^{-3} \mathrm{~b}$ & $20.16 \pm 1.8 \times 10^{-3} \mathrm{a}$ \\
$\mathrm{r}$ & $0.18 \pm 9.1 \times 10^{-5} \mathrm{a}$ & $0.14 \pm 7.6 \times 10^{-5} \mathrm{~b}$ \\
\hline
\end{tabular}

Nilai pada baris yang sama dan diikuti oleh huruf yang sama tidak menunjukkan beda nyata ( $T$ test $\alpha=5 \%$ )

Nilai $R_{0}$ dan GRR menunjukkan adanya kesesuaian hidup serangga terhadap tanaman inangnya. Apabila nilai GRR dan $\mathrm{R}_{0}$ rendah, hal tersebut menunjukkan kurang sesuainya inang dan sebaliknya nilai R0 dan GRR tinggi menunjukkan inang sesuai untuk tungau (Kurniawan, 2007). Dalam kasus penelitian ini, nilai GRR, $\mathrm{R}_{0}$ dan $\mathrm{r}$ D. floridanus lebih tinggi pada kultivar Queen dibandingkan dengan kultivar Cayenne yang berarti tungau ini lebih sesuai hidup di kultivar Queen.

\section{SIMPULAN}

Tungau D. floridanus memiliki lima stadia yaitu telur, larva, protonimfa, deutonimfa, dan imago. Pada kultivar Queen, masa larva dan protonimfa $D$. floridanus lebih singkat dibandingkan pada kultivar Cayenne. Nilai variabel pertumbuhan populasi menunjukkan kultivar Queen lebih sesuai untuk $D$. floridanus dibandingkan kultivar Cayenne.

\section{DAFTAR PUSTAKA}

[BPS] Badan Pusat Statistika. 2018. Statistik Tanaman Buah-buahan dan Sayuran Tahunan 2017. Jakarta (ID): Badan Pusat Statistika.

Amjad M, Peters DC. 1992. Survival, development, and reproduction of Turnip aphid (Homoptera: Aphididae) on oil seed Brassica. J Econ Entomol. 85(5): 2003-2007.

Baker EW, Pritchard AE. 1956. False spider mites of the genus Dolichotetranychus (Acarina: Tenuipalpidae). Hilgardia. 24: 357-381.

Begon M, Mortimer M. 1981. Population Ecology: A Unified Study of Animals and Plants. Sunderland (GB): Sinauer Associated Inc Publisher.

Ehara S. 1966. The Tetranychoid Mites of Okinawa Island (Acarina: Prostigmata). Hokkaido (JP): Hokkaido University.

Evans GA, Cromroy HL, Ochoa R. 1993. The tenuipalpidae of honduras (Tenuipalpidae: Acari). Flor Entomol. 76: $126-155$. 
Helle W, Pijnaker LP. 1985. Parthenogenesis, chromosomes, and sex. Di dalam: Helle W, Sabelis MW, editor. Spider Mites Their Biology, Natural Enemies, and Control. Volume 1A. Tokyo (JP): ELSEVIER. p 129-148.

Kurniawan HA. 2007. Neraca kehidupan kutukebul, Bemisia tabaci Gennadius (Hemiptera: Aleyrodidae) biotipe-B dan non-B pada tanaman mentimun (Curcumis sativus L.) dan cabai (Capsicum annuum L.) [tesis]. Bogor (ID): Sekolah Pascasarjana IPB.

Laba IW, Rauf A, Kartosuwondo U, Soehardjan M. 2006. Parameter kehidupan dan demografi kepik Dinocodoris hewetti (Dist.) (Hemiptera: Tingidae) pada dua varietas lada. J LITTRI. 12(3): 121-127.

Mawan A. 2013. Pengaruh cendawan endofit terhadap biologi dan statistik demografi wereng batang cokelat [tesis]. Bogor (ID): Fakultas Pertanian, Institut Pertanian Bogor.

Mohammed MI, Zaher MA, Hassan MF. 1982. Observations on Cheyletus cacahuamilpensis, a predator of the tenuipalpid mite Dolichotetranychus floridanus. Entomophaga. 27: 343-347.

Prabheena P, Ramani N. 2015. Incidence of Dolichotetranychus floridanus (Acari:Tenuipalpidae) on Arecanut Planantion. Intl J of Agric Tech. 11(4): 89-893.

Poli RCD. 1991. The Biology of The False Spider Mite Dolichos tetranychus floridanus: A Pest of Pineapples in Center Queensland. Queensland (AU): University of Central Queensland.

Price PW. 1997. Insect Ecology. $3^{\text {th }}$ ed. New York (US): John Wiley \& Sons.

Southwood TRE, Henderson PA. 2000. Ecological Method. $3^{\text {th }}$ ed. Oxford (GB): Blackwell Science.

Young AM. 1982. Population Biology of Tropical Insect. New York (US): Plenum Pr. 